\title{
TECTÔNICA DE NAPPES NA REGIÃO DE OURO FINO, CONCEIÇÃO DO MATO DENTRO, MG
}

\section{PEDRO ÂNGELO ALMEIDA-ABREU*, NILZA HELENA QUINTÃO**, VASSILY KHOURY ROLIM**, FRANCISCO ROBÉRIO DE ABREU* e PIERRE MUZZI MAGALHÃES***}

\begin{abstract}
NAPPE TECTONICS IN OURO FINO REGION, CONCEIÇÄO DO MATO DENTRO, MG. The region around the District of Ouro Fino (Conceição do Mato Dentro, MG) is located on the southeastern border of the Espinhaço mountain range, where granite-gneissic (Basal Complex) and low grade metasedimentary rocks can be found (Metasedimentary Sequences I and II). Fine to coarse clastic rocks (phyllites, quartzites, metaconglomerates) dominate in these sequences. Basic metavolcanic rocks are less frequent. The rocks in this region are intensively deformed showing a strong tangencial, with mass transport from east to west shown by the general tectonic structures, syn-mylonitic foliation parallel to $S_{0}$, and also by smaller structures like pressure shadows, grain rotation, $\mathrm{S}$ and $\mathrm{C}$ surfaces, stretching lineation, among others. The type of the deformation is non-coaxial and heterogeneous. The tectonic stacking of similar stratigraphic unities, individualized by slices of gneissic mylonitic rocks, characterize structures formed by nappe-tectonics.
\end{abstract}

INTRODUÇÃO Na região do Distrito de Ouro Fino (Conceição do Mato Dentro, MG, Fig. 1) afloram rochas de caráter cristalino (Complexo Basal) e rochas metassedimentares de baixo grau metamórfico, dominantemente quartzíticas (seqüências metassedimentares I e II; Machado et al. 1986).

Na área, assim como em toda a borda sudeste da Serra do Espinhaço Meridional, ressalta-se uma intensa deformação de caráter tangencial, com transporte de massa para W, regionalmente reconhecida por Guimarães (1951), Costa (1976), Braun \& Batista (1978) e Herrgesell \& Pflug (1985). Esta deformação é denotada pela geração de contatos anormais entre as unidades estratigráficas maiores, por meio de superfícies de cavalgamento de baixo a médio ângulo, e pelo desenvolvimento sincrônico de uma foliação subparalela a $\mathrm{S}_{0}$ e uma lineação mineral ou de estiramento orientada segundo a direção do transporte tectônico.

GEOLOGIA REGIONAL Na borda leste do Espinhaço Meridional residem as discussões mais polêmicas sobre a geologia dessa cordilheira, especialmente no que tange às relações estratigráficas e tectônicas entre as unidades rochosas dos supergrupos Minas e Espinhaço.

Muitos trabalhos têm sido apresentados sobre esta questão (e.g. Assis 1982, Uhlein 1982, Assis \& Marini 1983, Dossin et al. 1984), mas, sem dúvida, os mais abrangentes e detalhados foram promovidos pelo professor Pflug da Universidade de Freiburg, quer em trabalhos pessoais (Pflug 1965, Pflug 1968, Pflug et al. 1969, Pflug \& Renger 1973), quer em trabalhos de tese sob sua orientação (Renger 1972, Hoppe, 1978, Paternoster 1979, Herrgesell 1985).

Este trabalho aborda a faixa centro-sul da Quadrícula de Ouro Fino (Fig. 1), onde podem ser reconhecidas três unidades estratigráficas maiores:

Complexo Basal Constitui o embasamento cristalino da região e foi assim denominado por Bastos Neto (1982). Congrega predominantemente rochas granito gnássicas semelhantes ao "Granito de Gouveia" (Pflug \& Carvalho 1964) e, subordinadamente, gnaisses de composição tonalítica. Produtos miloníticos dessas rochas são abundantes nas zonas de cisalhamento, aflorando sob a forma de diferentes termos petrográficos, até "xistos sericíticos".

Seqüência Metassedimentar I É constituída por conjuntos de sericita xistos com quantidades variáveis de quartzo, intercalados com quartzitos laminados, puros e micáceos, destacando-se topograficamente sob a forma de pequenos hog backs alinhados na direção N-S. Essa unidade é correlacionável ao Supergrupo Rio Paraúna de Fogaça et al. (1984), considerando-se a similaridade litopetrográfica e a continuidade física em direção NNW até a região de Gouveia, conforme o mapa de Pflug \& Renger (op. cit.).

Seqüência Metassedimentar II Compõe o principal acidente geográfico da área (a Serra de Ouro Fino), definindo expressivos e extensos hog backs orientados na direção NNW-SSE com escarpas e desníveis de até $300 \mathrm{~m}$. Litologicamente, é constituída por quartzitos - às vezes metarenitos, geralmente de granulação fina a média, muitas vezes com grânulos e seixos esparsos. Comumente aparecem intercalações decimétricas até decamétricas de metaconglomerados, geralmente polimíticos, em horizontes, bancos ou camadas de extensão lateral da ordem de centenas de metros, às vezes com interdigitações evidentes, sendo as rochas dominantes no oeste da área, no vale do Rio Parauninha. A continuidade física para $\mathrm{N} \mathrm{e} \mathrm{NW} \mathrm{com} \mathrm{as} \mathrm{rochas}$ quartzíticas do Supergrupo Espinhaço é representada em todos os mapas geológicos regionais existentes (e.g. Pflug \& Renger op. cit.). Isto é confirmado também pela similaridade entre os metaconglomerados da região de Ouro Fino com aqueles largamente conhecidos e descritos nos municípios de Diamantina e Datas, e agrupados na Formação Sopa-Brumadinho, até por seu caráter diamantífero. Outro aspecto similar às seqüências inferiores do Supergrupo Espinhaço é a presença de corpos decimétricos a métricos de filitos hematíticos (metavulcanitos sin-sedimentares).

Completam o quadro estratigráfico pré-cambriano da região de Ouro Fino corpos de rochas metaígneas básicas metadiábasios e similares - na forma de extensos diques (de dezenas até a ordem de $1.000 \mathrm{~m}$ de extensão) ou de soleiras, consideradas como rochas intrusivas sin a tardi-tactônicas.

\footnotetext{
* Centro de Geologia Eschwege, IGC-UFMG. Rua da Glória 297, Caixa Postal 51, CEP 39100, Diamantina, MG, Brasil

** Departamento de Geologia, IGC-UFMG. Av. Antônio Carlos, 6627, CEP 31270, Belo Horizonte, MG, Brasil

*** Departamento de Geologia, Curso de Pós-Graduação/UFOP. Praça Tiradentes 20, CEP 35400, Ouro Preto, MG, Brasil
} 


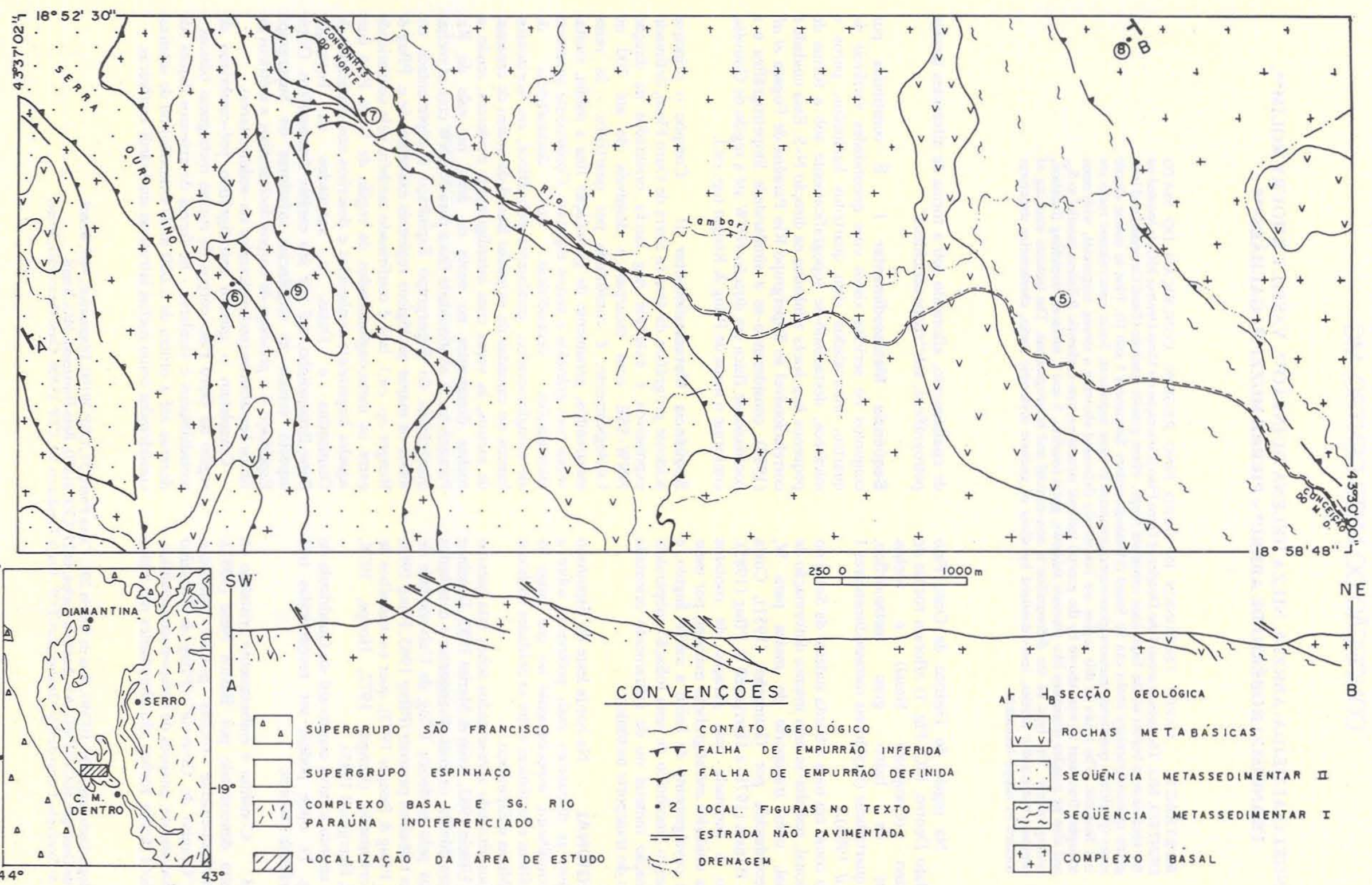


TECTÔNICA Análise Estrutural As rochas da região de Ouro Fino exibem evidências de dois episódios de deformação: um, de caráter dúctil-rúptil $\left(\mathrm{D}_{1}\right)$; e outro, de caráter essencialmente rúptil $\left(\mathrm{D}_{2}\right)$, desenvolvidas progressivamente em um mesmo evento de deformação (En).

A primeira, mais marcante, é responsável pela estruturação tectônica geral de toda a borda sudeste da Serra do Espinhaço Meridional (Herrgesell \& Pflug op. cit., Almeida Abreu et al. 1986, Hartmann et al. inédito), obliterando quase todas as estruturas primárias das seqüências metassedimentares, como também as estruturas deformacionais mais antigas do Complexo Basal.

Vestígios locais destas últimas podem ser reconhecidas pelo bandamento dos gnaisses. Mais raramente, observam-se também preservadas típicas estruturas fluidais.

$\mathrm{Na}$ Seqüência Metassedimentar I observam-se, como estruturas primárias preservadas, só ocorrências pontuais de estratificação plano-paralela denunciada por variações granulométricas e litológicas associadas a superfícies Sn. Na Seqüência Metassedimentar II são observadas estruturas primárias (estratificações plano-paralela e cruzadas) em domínios mais distantes das principais zonas de cisalhamento.

A estrutura de maior distribuição nas rochas da área é uma foliação (Sn), estrutura planar e penetrativa, paralela a subparalela ao acamamento. Aparece quase sempre de forma conspícua, especialmente nas litologias pelíticas e micáceas, e, de maneira mais discreta, nas rochas competentes (granitóides e quartzitos puros) quando nas proximidades das principais zonas de cisalhamento.

Esta foliação $\mathrm{Sn}$ pode ser chamada também de xistosidade no conceito de Hobbs et al. (1976) e, nas zonas de cisalhamento, assume o caráter de foliação milonítica freqüentemente associada a estruturas do tipo "S-C" (Berthé et al. 1979) de ordem centimétrica a decimétrica. Estruturas semelhantes aparecem também em escala microscópica (Fig. 5), muitas vezes do tipo mica fish (Lister \& Snoke 1984).

Invariavelmente, sobre a superfície Sn, observa-se uma pronunciada lineação de estiramento $(\mathrm{Ln})$ ressaltada especialmente pelas micas brancas (sericita/muscovita) e por seixos fortemente estirados nas rochas conglomeráticas. Notável em Ln é sua regularidade quase sempre orientada aproximadamente na direção W-E, como mostrado na figura 2.

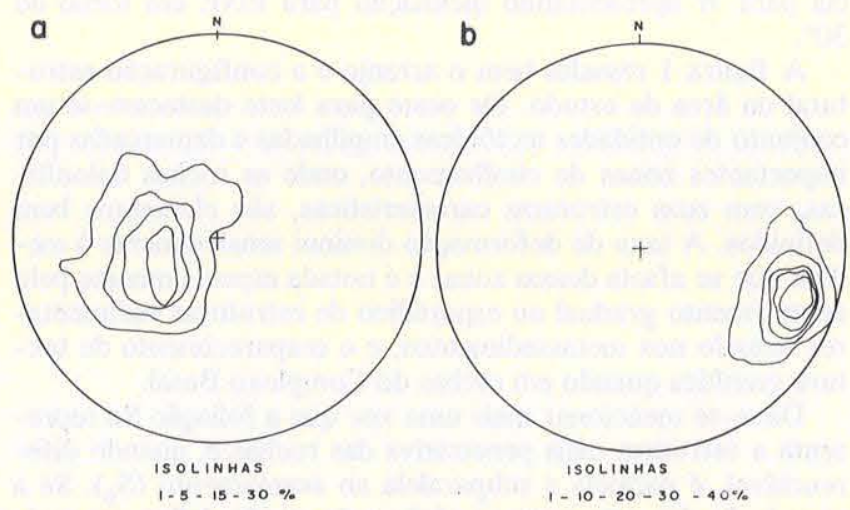

Figura 2 - Diagramas de freqüência (hemisfério inferior) para pólos de: a) Sn (220 medidas) e b) para pólos de Ln (126 medidas), obtidas nas rochas da região de Ouro Fino

A foliação Sn, por sua vez, apresenta variações em sua orientação espacial, pois, sendo uma estrutura planar, acompanha as ondulações dos grandes cavalgamentos e também a reestruturação com o basculamento tardio de blocos. Assume da mesma forma as variações decorrentes das irregularidades dos planos dos grandes falhamentos (rampas laterais, por

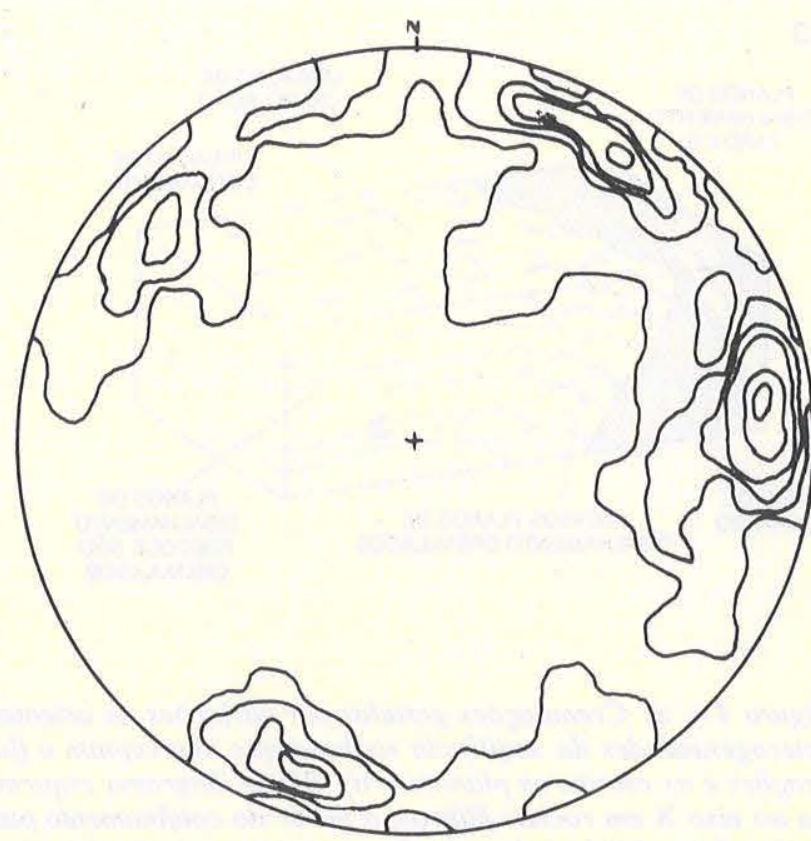

I SOLINHAS - 0,4-2,38-4,28-5,24-8,09-10\%

Figura 3 - Diagrama de isolinhas (hemisfério inferior) de lineações de crenulação da área de Ouro Fino e regiões adjacentes (quadrículas de São Sebastião do Bonsucesso, Alvorada de Minas e Itapanhoacanga, em rochas dos supergrupos Minas e Espinhaço)

exemplo), que podem ser controladas ou não pelas irregularidades morfológicas do embasamento (Fig. 2). Essas feições caracterizam, no conjunto, a heterogeneidade da deformação.

Eventualmente nos xistos da Seqüência Metassedimentar I, aparecem dobras apertadas - geralmente isoclinais assimétricas de ordem centimétrica. Essas dobras são intrafoliais, com ou sem raízes, e se encontram ressaltadas nos níveis que mostram variações composicionais (formações ferríferas bandadas, por exemplo). Seus eixos podem ser perpendiculares a $\mathrm{Ln}$ (dobra tipo $y$ ) ou paralelas à lineação (tipo $x$ ) e evidenciam o caráter interestratal da deformação.

Outra estrutura, que aparece impressa sobre a foliação Sn, é a crenulação. Apesar de não ser abundante, é uma estrutura muito freqüente, especialmente nas rochas incompetentes (filitos principalmente). Pode-se dizer que são diferentes tipos de crenulação, tanto no aspecto genético, quanto nas relações temporais com as demais estruturas tectônicas, e podem configurar lineações perpendiculares, oblíquas ou paralelas à lineação de estiramento (Ln), e serem penetrativas ou não (Fig. 3).

Sobre essas crenulações, deve-se destacar os seguintes pontos:

a) $\mathrm{O}$ aparecimento dessas estruturas é ocasional e sua distribuição não mostra nenhuma regularidade.

b) As crenulações enrrugam a lineação de estiramento ou a recortam parcialmente.

c) Essas crenulações são restritas a superfícies localizadas ou níveis de pequena espessura (filitos ou níveis micáceos).

Pelas observações de campo, é possível admitir três fenômenos principais geradores dessas crenulações:

1. Variações locais na orientação do elipsóide de deformação finita determinando uma nova posição nos planos de cisalhamento que passam a cortar os antigos planos, isto é, o fluxo laminar dos planos de cisalhamento é modificado por hetero- 
a

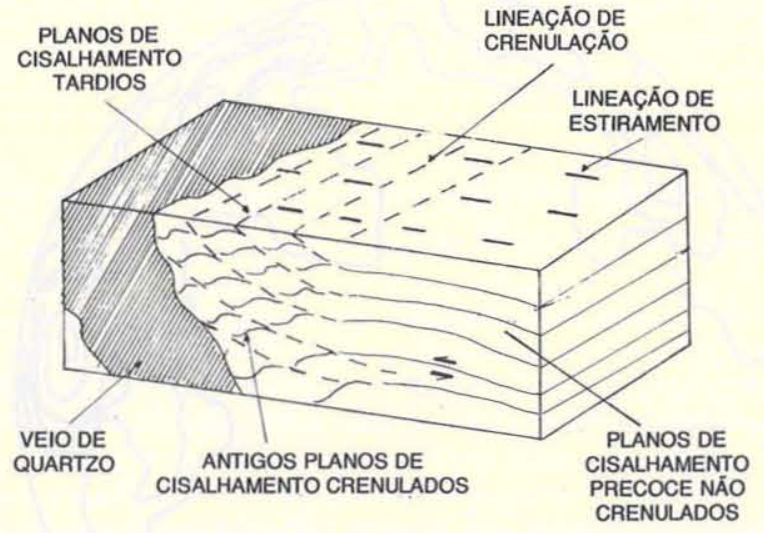

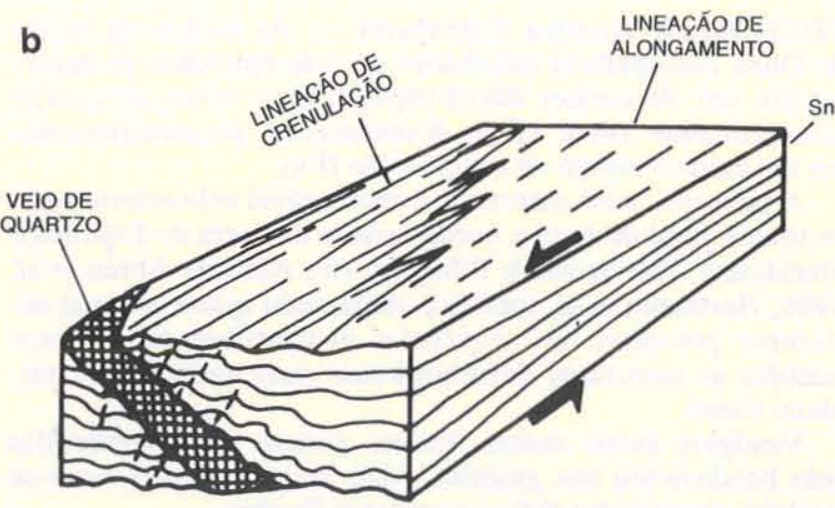

I IM

Figura 4 - a) Crenulações geradas por variações na orientação do elipsóide de deformação finita. As variações são causadas por heterogeneidades da seqüência rochosa que interceptam of fluxo laminar do cisalhamento. Notar as relaçöes espaciais entre as lineações e as estruturas planares. b) Bloco-diagrama esquemático mostrando o desenvolvimento "pontual" de crenulaçôes paralelas ao eixo $\mathrm{X}$ em rochas filíticas, a partir do confinamento parcial das camadas por veio de quartzo. Observar a constrição das camadas determinada pelo veio de quartzo e a relação dos planos de clivagem com a lineação de crenulação (que é paralela a Ln) que se desenvolve somente nas adjacências do elemento rígido

geneidades na rocha (veios ou bolsões de quartzo, por exemplo), que deslocam os antigos planos para posições onde passam a ser cortados pelos incrementos cisalhantes tardios da deformação (Fig. 4a). Estas crenulações fazem ângulo alto com os planos de cisalhamento.

2. Durante os processos de cisalhamento, os estratos em movimento são parcialmente confinados por elementos mais rígidos que interceptam sua trajetória (por exemplo, veios de quartzo; rápidas variaçőes litológicas), gerando rugosidade ou mesmo crenulaçōes verdadeiras orientadas segundo Ln (Fig. 4b).

3. O estiramento generalizado das rochas associado a movimentos interestratais diferenciados (níveis quartzosos e micáceos), promovendo ondulações e rugosidades sobre as superfícies definidas por micas.

Pelo exposto, fica caracterizado sua relação genética com o desenvolvimento do cisalhamento em regime dúctil (Lacassin 1984), considerando que parte das crenulações observadas sāo rugosidades alinhadas sobre níveis milimétricos de micáceos e que não se impōem, em geral, às faixas quartzosas, denotando o estado de plasticidade do quartzo durante o processo de desenvolvimento das crenulações (considerando, neste caso, que se tenham desenvolvido por fluxo contracional tardio).

As microestruturas são também muito abundantes, especialmente nas rochas do Complexo Basal. Sombras de pressâo aparecem nas bordas dos grẩos de feldspatos, quartzo e minerais opacos, e são constituídas por quartzo (Fig. 6) e/ou micas (Fig. 7), finalmente recristalizados. Em seções delgadas dos metassedimentos, as micas fish sâo freqüentes (Fig. 5). Destacam-se ainda fraturas antitéticas e o estiramento mineral generalizado.

Essas microestruturas comprovam a não-coaxialidade da deformação $\mathrm{D}_{1}$ bem como a rotação sinistrógira de grãos, indicando o sentido de transporte de leste para oeste, utilizandose os critérios de Berthé et al. (op. cit.) e Simpson \& Schmid (1983).

A deformação $\mathrm{D}_{2}$ é de caráter eminentemente rúptil e se manifesta espaçadamente como falhas inversas e normais de alto ângulo com direção aproximadamentee N-S e E-W, respectivamente, e onde podem aparecer estrias de falha e rochas cataclásticas (brecha). Comum também é o aparecimento de uma clivagem de fratura (stricto sensu, no sentido de Hobbs et al. op. cit.), com planos orientados sistematicamente segundo a direção N-S a NNE-SSW com mergulho forte $\left(65^{\circ}\right.$ a $\left.80^{\circ}\right)$ para leste. As estruturas de $\mathrm{D}_{2}$ cortam todas as estruturas dúcteis de $\mathrm{D}_{1}$.

As deformações $D_{1}$ e $D_{2}$ exibem polaridade idêntica (transporte de leste para oeste) marcada pela lineação de estiramento e estrias de falha, respectivamente, e representam dois episódios de um mesmo evento, sendo a fase $\mathrm{D}_{2}$ uma manifestação tardia de uma deformação progressiva, quando as seqüências rochosas atingiram um nível crustal mais superior no perfil do edifício orogênico.

"Falhas" e Nappes As falhas de cavalgamento representam as principais estruturas da área e são responsáveis pela estruturação e distribuição das grandes entidades tectônicas da região. Mostram-se orientadas na direção NNW com vergência para W apresentando inclinação para ENE em torno de $30^{\circ}$.

A figura 1 ressalta bem o arranjo e a configuração estrutural da área de estudo. De oeste para leste destacam-se um conjunto de entidades tectônicas empilhadas e demarcadas por importantes zonas de cisalhamento, onde as rochas miloníticas, com suas estruturas características, são elementos bem definidos. A taxa de deformação diminui sensivelmente à medida que se afasta dessas zonas e é notada especialmentee pelo aparecimento gradual ou esporádico de estruturas sedimentares quando nos metassedimentos, e o reaparecimento de textura granítica quando em rochas do Complexo Basal.

Deve-se mencionar mais uma vez que a foliação Sn representa a estrutura mais penetrativa das rochas e, quando diferenciável, é paralela a subparalela ao acamamento $\left(\mathrm{S}_{0}\right)$. Se a associação das estruturas tectônicas da região define um regime de tectônica tangencial, conforme já ressaltaram Herrgesell \& Pflug (op. cit.), Almeida Abreu et al. (op. cit.), Tagliani et al. (no prelo), Hartmann et al. (s.d.), os nappes da área em estudo possuem o argumento estratigráfico irrefutável.

Ampla e espessas fatias do embasamento foram transportadas na base de conjuntos da Seqüência Metassedimentar II e posicionadas sobre espessos pacotes de metassedimentos da mesma seqüência. A espessura das rochas cristalinas transportadas varia da ordem de 1 a dezenas de metros. Localmente podem-se apresentar como "xenólitos tectônicos", ou seja, nas zonas de falha porções decimétricas a decamétricas de rochas do Complexo basal são removidas do pacote origi- 


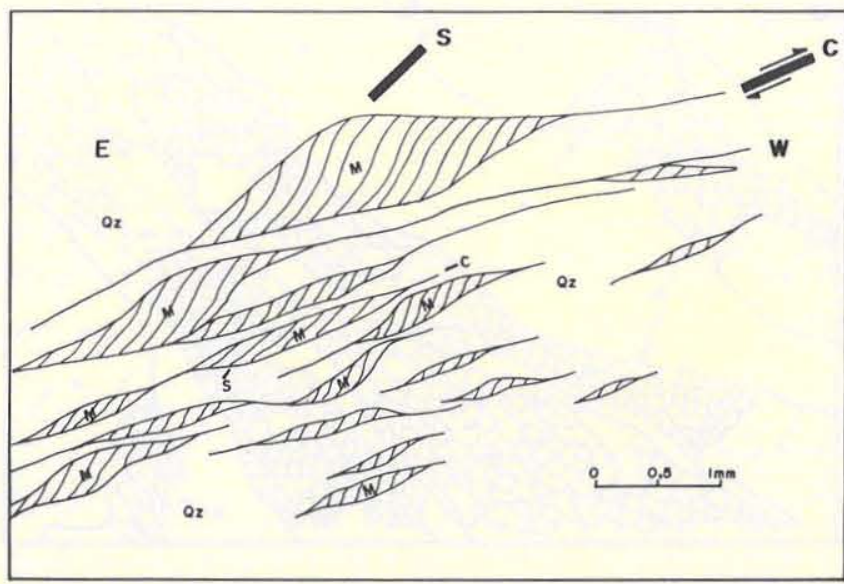

Figura 5 - Porfiroclastos sigmoidais de muscovita (mica fish) definindo as foliaçöes do tipo $S$ e $C$ (assinaladas). Esses indicadores cinemáticos mostram o movimento de $E$ para $W$. As micas estão envolvidas por massa de quartzo $(Q z)$ recristalizado. Rocha: quartzo-sericita xisto da Seqüencia Metassedimentar I (para localização, ver mapa geológico)

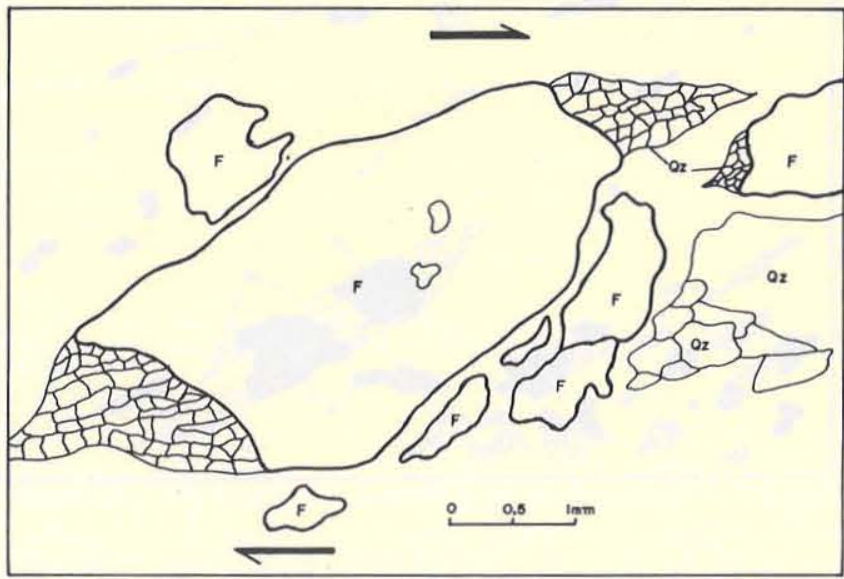

Figura 6 - Porfiroclastos de feldspato (F) com sombra de pressão assimétrica composta por quartzo $(Q z)$. $O$ sentido do movimento é indicado pelas setas. Rocha: granito gnáissico milonitizado (para localização, ver mapa geológico)

nal e completamente envolvidas pelos metassedimentos milonitizados.

As mencionadas estruturas e mesmo seu arranjo espacial se expressam no mapa geológico, de forma clara (Fig. 1), e são mais ressaltadas ainda pelas atividades erosivas diferenciais que geram uma superfície bem irregular, provocando a formação de "janelas" e "tetos" estruturais.

Nas zonas dos principais cisalhamentos e planos dos empurrões desenvolve-se um conjunto de rochas miloníticas no sentido de Sibson (1977), que se mostram bem diferenciadas nos litótipos do Complexo Basal, determinando a formação de rochas reconhecidas em campo com a descrição genérica de milonito-xistos e filonitos. Ȧ primeira vista, assemelham-se a metassedimentos pelíticos imaturos do tipo metagrauvacas. Por isso Soares Filho et al. (1986), em trabalho na mesma regiảo, relatam a presença de metassedimentos contendo feldspatos e apatita em contato direto com rochas granito gnáissicas, quando na realidade as passagens entre um e outro são graduais por variação textural-petrográfica de termos miloníticos.

Os produtos de deformação dos granitos gnáissicos geraram três tipos petrográficos principais, todos eles graduais entre si e para rochas pouco deformadas.

PROTOMILONITOS Exibem uma granulação grossa, foliacão incipiente e os feldspatos aparecem como porfiroclastos de maior ou menor tamanho. Este mineral apresenta extinção ondulante e às vezes maclas tectônicas ou em "chama". O quartzo aparece como porfiroclastos com forte extinção ondulante, às vezes total ou parcialmente cominuídos e também formando subgrãos com estreitos bordos recristalizados de granulação fina determinando a textura do tipo core and mantle (White et al. 1980). As mica-muscovita/sericita são em sua maioria geradas a partir da desestabilização dos feldspatos e formam pequenos caudais envolvendo os clastos maiores. $\mathrm{O}$ predomínio dos clastos sobre a recristalização é amplo. Ainda assim, verifica-se uma forte mudança das proporções minerais da rocha original para os protomilonitos, quando os $30 \%$ de microclina, $30 \%$ de plagioclásio e $30 \%$ de quartzo passam para cerca de $75 \%$ de microclina, $15 \%$ de quartzo e $10 \%$ de sericita-muscovita (Fig. 8), denotando uma diminuição nas quantidades de quartzo e o aparecimento das micas (Beach 1980).

MILONITOS Nestas rochas, a foliação é a estrutura mais marcante, determinada principalmente pelos minerais micáceos em faixas onduladas e anastomosadas em torno dos porfiroclastos de quartzo e feldspatos. Estes últimos se apresentam como clastos de granulação fina a média, estirados, indicando a lineação e freqüentemente com maclas tectônicas. Alterações do feldspato para micas é distinguível em muitos grãos. O quartzo mostra-se também, em geral, fortemente estirado e com extinção ondulante. As caudas alongadas são freqüentes e muitas vezes sem extinção ondulante, o que evidencia sua recristalização total (Figs. 5 e 7 a e b).

As sombras de pressão são abundantes e crescentes com o aumento da deformação, constituídas por quartzo e/ou sericita, esta última dominando nas rochas com grau de milonitização mais acentuado. As fraturas dos grãos maiores são preenchidas também por micas e quartzo.

FILONITOS Nestas rochas, a granulação é muito fina. Os processos de milonitizaçāo são extremos, alterando quase totalmente a mineralogia original da rocha, quando passa a predominar amplamente a sericita-muscovita em bandas ou níveis, definindo a foliação e também a lineação de estiramento. O quartzo aparece em pequenas quantidades, totalmente recristalizado, concentrando-se em lâminas e filmes descontínuos. O feldspato é raro, aparecendo somente como pequenos clastos reliquiares de forma ocelar. Minerais opacos aparecem em pequenas manchas ou como porfiroclastos fraturados e estirados, exibindo sombras de pressão preenchidas pela sericita (Fig. 9).

Além dos processos de deformação impostos para a geração das rochas miloníticas, associa-se a eles um pronunciado processo de microclinização. Enquanto nas rochas granitognáissicas do Complexo Basal da área microclina e plagioclásio coexistem em proporções similares na ordem de $30 \%$, em seus produtos miloníticos a microclina compõe praticamente a totalidade dos feldspatos.

Esse fato sugere uma importante percolação de fluidos ri$\cos$ em potássio. A relação de tempo da mobilização e a origem dessas soluções são dimensionáveis pelo menos parcialmente, conforme os parâmetros descritos a seguir.

A microclina representa o único feldspato das rochas com avançado processo de deformação, ou seja, foi preservada dos processos de sericitização. Ao mesmo tempo apresentam diferentes feições de mineral deformado. Nas rochas metabási- 

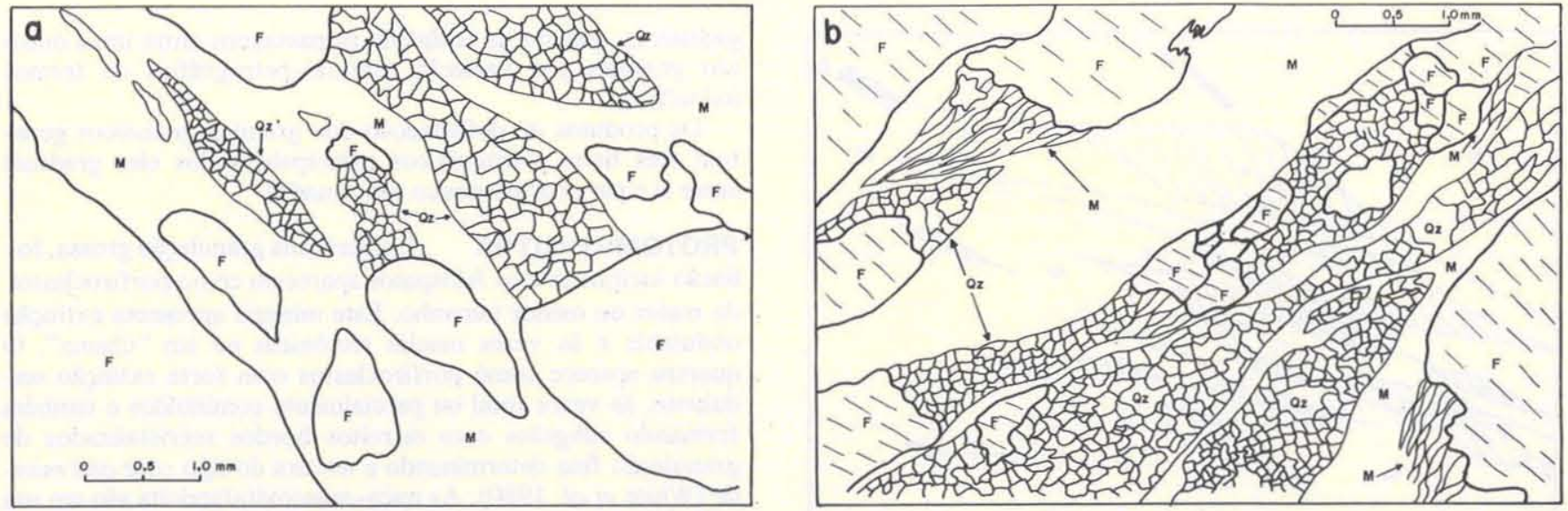

Figura 7 - a e b Estágios intermediários de milonitização das rochas granito-gnáissicas. Os feldspatos $(F)$ vão-se reduzindo a clastos de granulação menor. $O$ quartzo $(Q z)$ se recristaliza totalmente formando ribbons, sombras de pressâo e preenchendo fraturas. As micas (M) formam "caudais" envolvendo os porfiroclástos, definindo a foliação e substituindo total ou parcialmente os feldspatos (para localização, ver mapa geológico)

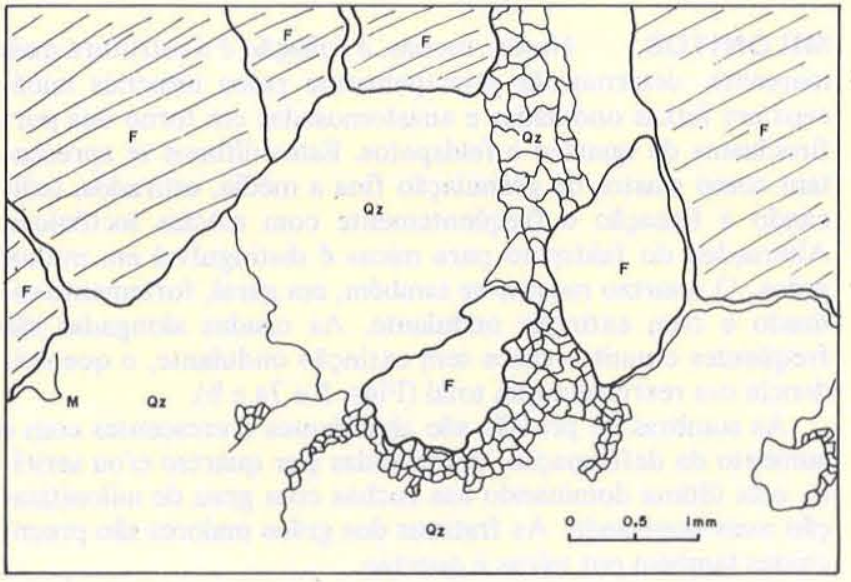

Figura 8 - Protomilonitos de rocha granito-gnáissica do Complexo Basal. Evidencia o estágio inicial da deformação. $O$ feldspato $(F)$ mostra-se fraturado e são microclinas. $O$ quartzo $(Q z)$ mostra-se como porfiroclastos com extinção ondulante $e$ recristalizados em pequenos grâos. Muscovita-sericita (M) começam a aparecer nos bordos dos feldspatos (para localização, ver mapa geológico)

cas - suíte de rochas subvulcânicas do tipo diabásios e equivalentes, que aparecem cortando todas as seqüências da região sob a forma de diques ou sillis - ressaltam-se com microclinas com inclusões de epídotos sugerindo a potassificação de plagioclásios.

Admitir processos de triclinização de outro feldspato potássico (White \& Mawer 1986) é inviável, pois não sẫo observadas espécies diferentes de $\mathrm{K}$-feldspato nas rochas granitognáissicas pouco ou não deformadas.

Completa este quadro a presença freqüente de veios pegmatóides compostos por microclina rósea, quartzo e, subordinadamente, hematita, associados aos milonitos e suas regiões de contato.

Por tudo isso, é razoável admitir-se que, nas zonas de cisalhamento que envolvem o transporte de fatias de rochas granito-gnáissicas, ocorreu uma constante mobilização de

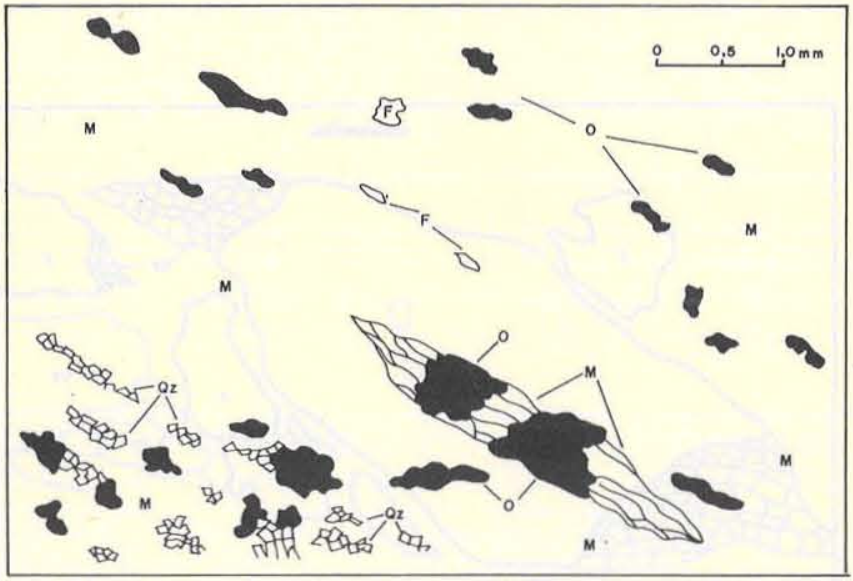

Figura 9 - Filonito: estágio final de milonitização. As micas (M) compõem grande parte da rocha, isolando porfiroclastos de opacos $(O)$. $O$ quartzo $(Q z)$ se concentra em pequenas bandas e o feldspato $(F)$ é reliquiar, formando pequenos clastos ocelares (5\% microclina; $10 \%$ quartzo, e $85 \%$ sericita) (para localização, ver mapa geológico)

fluidos enriquecidos em soluçōes potássicas sin-tectônicas, persistindo até os estágios finais de deformação; cumpre lembrar, ainda, que a ambiência metamórfica dessas zonas é favorável à geração desses mobilizados. Admitir que essas soluções são oriundas de fontes externas não tem sustentação, considerando-se que nos grandes cisalhamentos e planos de cavalgamento que envolvem somente metassedimentos elas não estão presentes.

CONCLUSÕES A região do Distrito de Ouro Fino exibe pelo menos dois grandes nappes empilhados tectonicamente, com transporte de leste para oeste.

A associação de estruturas menores indicam bem o sentido do transporte tectônico, assim como um regime de deformação contínua e dúctil a que foram submetidas as rochas da região, denunciando também a heterogeneidade e a não-coaxialidade da deformação (Berthé et al. op. cit., Lister \& 
Snoke op. cit.).

Distante cerca de $2 \mathrm{~km}$ do front atual dos nappes, para W, afloram espessas seqüências de rochas metassedimentares pertencentes ao Supergrupo Espinhaço, exibindo arranjo e estruturação de entidades autóctones (camadas sub-horizontais e deformação incipiente); tal fato evidencia a interceptação, no local, de seqüências de dois níveis crustais diferentes e pode indicar também que os nappes de Ouro Fino sejam os mais ocidentais, preservados da erosão, no contexto da borda leste do Espinhaço Meridional.

As fatias de rochas cristalinas do Complexo. Basal representam um importante controle estratigráfico para a definição dos nappes e se constituem em fato inusitado na tectônica de toda a borda SE da Serra do Espinhaço Meridional. Essas "lascas" de infracrustais devem ter sido arrancadas de altos topográficos ou estruturais do embasamento durante a propagação dos planos de cavalgamento na forma descrita por Hatcher Jr. \& Williams (1986). A microclinização generalizada indica a presença de fluidos ligados à tectônica.

As relações da foliação $\mathrm{Sn}$ e da lineação de estiramento Ln indicam a polaridade constante do transporte tectônico, com manifestações tardias de acomodação de blocos por basculamento ou a formação de rampas laterais.

É importante destacar também que o arranjo estrutural observado, assim como os elementos estruturais menores presentes nas rochas da região, é semelhante aos descritos em toda a borda sudeste do Espinhaço Meridional (Herrgesell \& Pflug op. cit., Almeida Abreu et al. op. cit., Hartmann et al. inédito, até nas seqüências caracterizadas pelos mencionados autores como pertencentes ao Supergrupo Minas, o que sugere, ou mesmo indica, a contemporaneidade com as seqüências do Supergrupo Espinhaço, conforme proposto por Pflug (1965). Considere-se para esta assertiva os elementos descritos pelos mencionados autores, como a ausência de estruturas de fases ou episódios específicos a um ou outro conjunto, e as evidências de variaçōes litofaciológicas entre unidades dos dois supergrupos.

Faz-se necessário mencionar, ainda, que várias das estruturas reconhecidas nesta região são observadas também em diferentes porções da Serra do Espinhaço como ocorrência pontual, e seu tratamento diferenciado pode levar à suposição de diferentes fases de deformação na edificação da cadeia orogênica.

Agradecimentos Expressamos nossos agradecimentos aos professores L.G. Kanuer (C.G. Eschwege), A. Schrank (Unicamp) e M.B. Hartmann (Unifor), pelas críticas e sugestões. Às senhoritas Marta Maria Couto e Maria Helena Seabra, pela datilografia; e ao senhor Geraldo Dupim, pelos desenhos. Para a realização deste trabalho, foi utilizada a infraestrutura do Centro de Geologia Eschwege com o apoio direto ou indireto de seus funcionários.

\section{REFERÊNCIAS BIBLIOGRÁFICAS}

ALMEIDA-ABREU, P.A.; FERNANDES, P.C. de O.; KANUER, L.G.; HARTMANN, M. B.; DONATO, M.T.R.; SCHORSCHER, H.D. 1986. Elementos da zona de cisalhamento dúctil da borda oriental da Serra do Espinhaço, Minas Gerais. In: CONGR. BRAS. GEOL., 34, Goiânia, 1986. Anais... Goiânia, SBG. v. 2, p. 1219-1231.

ALVES, C.J.; MARIANO, J.V.F.; PLESCHETTE, C. 1986. Geologia da Porção Sul da Quadrícula de São Sebastiāo do Bonsucesso, Conceicāa do Mato Dentro-MG. Belo Horizonte, 84 p. (Relatório de Graduação, Dep. Geol. Univ. Fed. Minas Gerais).

ASSIS, L.C. de. 1982. Estratigrafia, tectônica e potencialidade mineral das unidades Pré-Cambrianas da região de Serro-MG (Quadrícula de Mato Grosso). Brasília, 149 p. (Dissertação de Mestrado, Dep. Geoc. Univ. de Brasília, UnB).

BARBOSA, O. 1954. Evolution du Geosynclinal Espinhaço. In: GEOL. INTERN. CONGR., 19, Alger, 1954. Annals... Alger, Sect. XIII, Fasc. 14, p. 17-36.

BASTOS NETO, A.C. 1982. Geologia das Quadrículas de Dom Joaquim e parte sul de Ribeiräo da Barra - borda leste da Serra do Espinhaço Meridional-MG. Rio de Janeiro, 111 p. (Dissertação de Mestrado, Inst. Geoc., UFRJ).

BEACH, A. 1980. Retrogressive metamorphic porcesses in shear zones with special reference to the Lewissian Complex. J. Struct. Geol., 2(1/2):257-263.

BERTHÉ, D.; CHOUKROUNE, P.; JEGOUZO, P. 1979. Orthogneiss, mylonite and non-coaxial deformation of granites: the example of the South Amorican shear zone. J. Struct. Geol., 1:31-42.

BOYER, S.E. \& ELLIOT, D. 1982. Thrust systems. Am. Assoc. Pet. Geol. Bull., 66(9): 1190-1230.

BRAUN, O.P.G. \& BAPTISTA, M.M. 1978. Consideraçōes sobre a geologia do Pré-Cambriano da Região Sudeste e parte da Regiäo Centro-oeste do Brasil. In: REUNIÂO PREPARATÓRIA SIMP. CRÁTON SÄO FRANCISCO, Salvador, 1978. Anais... Salvador, SBG, p. 225-350. (Publicação Especial 3).

BURG, J.P. \& LAURENT, Ph. 1978. Strain analyses of a shear zone in a granodiorite. Tectonophysics, 47:15-42.

CARVALHO, A.S. de 1982. Geologia e gênese das mineralizaçôes de quartzo no Espinhaço Meridional (MG Brasil). Brasília 94p. (Dissertação de Mestrado, Dep. Geoc., UnB).

COSTA, M.T. da. 1976. Nota explicativa sobre o Mapa Geológico de Minas Gerais. Belo Horizonte, Publ. IGA-MG.

DERBY, O.A. 1906. The Serra do Espinhaço, Brazil. J. Geol., 14:374-401.

ESCHWEGE, W.L.v. 1822. Geognostisches Gemalde von Brasilien und Wahrscheinliches Muttergestein der Diamanten. Berlim (Weimar Janges - Industrie-Comptoir). 44p.

ESCHWEGE, W.L.v. 1832. Breitage Zür Gebirgs-Kunde Brasilien. Berlim Reimer. 488p.

ESCHWEGE, W.L.v. 1833. Pluto Brasilienses - São Paulo. Livraria Edit. Itatiaia (tradução português Domício F. Murta, 1979). 2 v., $306+222 p$.
FOGAÇA, A.C.C.; ALMEIDA-ABREU, P.A. 1982. Depósitos de planícies de marés na Formação Sopa-Brumadinho (Proterozóico Inferior), Cordilheira do Espinhaço, Estado de Minas Gerais, Brasil. In: CONGR. LATINOAM. GEOL., 5, Buenos Aires, 1982. Anais... Buenos Aires. t. 2, p. 373-388.

FOGACA, A.C.C.; ALMEIDA-ABREU, P.A.; SCHORSCHER, H.D. 1984. Estratigrafia da Seqüência Supracrustal Arqueana na Porção Mediana-Central da Serra do Espinhaço, Minas Gerais, In: CONGR. BRAS. GEOL., 33, Rio de Janeiro, 1984. Anais... Rio de Janeiro, SBG. v. 6, p. 2654-2667.

FREYBERG, B.V. 1932. Ergebnisse Geologischer Forschungen in Minas Gerais Brasilien. Stuttgart. N. Jb. Geol. Min. Palaont., Sonderbd., 2: 403p.

FREYBERG, B.V. 1934. Die Bodenschätze des Staates Minas Gerais, Brasilien. Stuttgart (schweitzerbart). 453p.

GUIMARÃES, D. 1951. Arqui-Brasil e sua evolução geológica. Rio de Janeiro, DNPM/DGM. (Boletim 88).

HARDER, E.C. \& CHAMBERLIN, R.J. 1915. The Geology of Central Minas Gerais, Brazil. J. Geol., 13:341-378 + 385-424.

HARTMANN, M.B.; TAGLIANI, T.R.; ALMEIDA-ABREU, P.A. s.d. Caracterization of the tangencial tectonics at the eastern edge of the Espinhaço Meridional Range (Itapanhoacanga-Conceiçẫo do Mato Dentro, MG.) (inédito).

HATCHER Jr., R.D. \& WILLIAMS, R.T. 1986. Mechanical model for single thrust sheets Part I: Taxonomy of crystalline thrust sheets and their relationships to the mechanical behavior of orogenic belts. Geol. Soc. Am. Bull., 97:975-985.

HERRGESELL, G. 1985. Uma margem continental proteroz6ica na Serra do Cipó Setentrional (Serra do Espinhaço Meridional) In: SIMP. GEOL. MINAS GERAIS, 3, Belo Horizonte, 1985. Anais... Belo Horizonte, SBG. Bol. 5, p. 1-15.

HERRGESELL, G. \& PFLUG, R. 1985. The thrust belt of the Southern Serra do Espinhaço, Minas Gerais, Brazil, Stuttgart, $Z$ Zbl. Geol. Palaont., Teil I(9/10):1405-1414.

HOBBS, B.E.; MEANS, W.D.; WILLIAMS, P.F. 1976. An outline of structural geology. New York, John Wiley \& Sons, Inc. 572p.

HOFFMANN, C. 1981. Geologische Geschichte, Metamorphose und Petrologie des Archaischen Komtinentalkernes (Prä-Espinhaço-Gesteine) der Südlichen Serra do Espinhaço, Minas Gerais, Brasilien. Freiburg. (Habil. Erlang. Ven. Lag. Miner. Petrol. Geowiss. Univ. Freiburg) 233p.

HOPPE A. 1978. Beiträge Zur Geologie und Paläogeographie der Su. llichen Serra do Espinhaço (Minas Gerais, Brasilien). Freiburg. (Dissertação These Doct. Univ. Freiburg.) 102p.

LACASSIN, R. 1984. Etude des mechanismes de deformation dans le versant nort de la nappe du Mont Rose (Alpes Suisses) et relation avec les grands chevauchements. Montpellier. (Thése Doct., Univ. Scie. Tech.) $221 \mathrm{p}$.

LISTER, G.S. \& SNOKE, A.W. 1984. S-C Mylonites. J. Struct. Geol., 6(6):617-638

MACHADO, A.F.; MUZZI-MAGALHÃES, P.; QUINTÃO, N.H. 
1986. Geologia da porção centro-sul da Quadrícula de Ouro Fino, Conceiçāo do Mato Dentro, MG. Belo Horizonte (Relatório de Graduação, Dep. Geol. Univ. Fed. Minas Gerais.) 92p.

MATTAUER, M. \& MERCIER, J.L. 1980. Microtectonique et grande tectonique. Mén. h. Sér. Soc. Géol. de France, Paris (10):153-186

MORAES, L.J. de \& GUIMARĀES, D. 1930. Geologia da região diamantífera do norte de Minas Gerais. An. Acad. Bras. Cienc. II: $153-186$

NICOLAS, A. 1984. Principes de Tectonique. Paris, Ed. Masson. 199p.

PATERNOSTER, K. 1979. Faziesvrzsahnung zwischen diamantführenden Freiburg.) $85 \mathrm{p}$.

PFLUG, R. 1965. A Geologia da parte Meridional da Serra do Espinhaço e zonas adjacentes, Minas Gerais. Rio de Janeiro, DNPM/DGM: 55p. (Boletim 226).

PFLUG, R. 1968. Observaçōes sobre a estratigrafia da Série Minas na Regiāo de Diamantina, MG. Rio de Janeiro, DNPM/DGM. 20p. (Notas Preliminares 142).

PFLUG, R. \& CARVALHO, R.T, de. 1964. A evoluçāo estrutural da regiäo de Gouveia, Serra do Espinhaço, Minas Gerais. Rio de Janeiro, DNPM/DGM. 37p. (Boletim 213).

PFLUG, R.; SCHOBBENHAUS, C.; RENGER, F. 1969. Contribuição à geotectônica do Brasil Oriental. Recife, Sudene/Div. Geol. 59p. (Série Especial 9).

PFLUG, R. \& RENGER, F. 1973. Estratigrafia e evolução da margem SE do Craton Sanfranciscano. In: CONGR. BRAS. GEOL., 27, Aracajú, 1973. Anais... Aracajú, SBG. v. 2, p. 5-19.

RENGER, F. 1972. As rochas ultrabásicas da Serra do Espinhaço, Minas Gerais. Rev. Bras. Geoc., 2(3):151-160.

RENGER, F. 1979. Evolução dos conceitos geológicos da Serra do Espinhaço. In: SIMP. GEOL. MINAS GERAIS, 1, Diamantina, 1979. Atas... Belo Horizonte, SBG. Bol. 1, p. 9-27.
SCHÖLL, W.U. \& FOGAÇA, A.C.C. 1979. Estratigrafia da Serra do Espinhaço na Regiâo de Diamantina (MG). In: SIMP. GEOL. MINAS GERAIS, 1, Diamantina, 1979. Atas... Belo Horizonte, SBG, Bol. 1, p. 55-73.

SIBSON, R.H. 1977. Fault rocks and fault mechanism. Struct. Geol. Soc. London, 133:191-213.

SIMPSON, C. \& SCHMID, S.M. 1983. An Evaluation of criteria to deduce the sense of movement in sheared rocks. Geol. Soc. Am. Bull., 94:1281-1283.

SOARES FILHO, B.S.; PINHEIRO, S.A.; SOUZA COSTA, M.N. 1986. Contribuição ao estudo de Geologia da Regiẫo de Conceição do Mato Dentro, MG. In: CONGR. BRAS. GEOL., 34, Goiânia, 1986. Anais... Goiânia, SBG v. 2.

TAGLIANI, T.R.; HARTMANN, M.B ; ALMEIDA-ABREU, P.A ; FERNANDES, P.C. de O. 1988. Estudo da deformação em metavulcanitos ácidos na Serra do Sapo (Cordilheira do Espinhaço Meridional-MG). Rev. Bras. Geoc. 18(1): (in press).

UHLEIN, A. 1982. Geologia e mineralizaçōes de cromita e itabiritos da Regiâo de Serro, MG. Brasília (Tese Mestrado, Dep. Geocien. UnB.) $189 \mathrm{p}$.

WHITE, J.C. \& MAWER, C.K. 1986. Extreme ductility of feldspars from a mylonite, Parry Sound, Canada. J. Struct. Geol., 8(2):133-143.

WHITE, S.H.; BURROWA, S.E.; CARRERAS, J.; SHAW, N.D.; HUMPHREYS, F.J. 1980. On mylonites in ductile shear zones. $J$. Struct. Geol., 2(2):175-187.

MANUSCRITO 514 Recebido em 17 de dezembro de 1987 Revisão aceita em 07 de abril de 1988 